\title{
Novel hypotheses emerging from GWAS in migraine?
}

\author{
Arn M. J. M. van den Maagdenberg ${ }^{1,2^{*}}$ (D), Dale R. Nyholt ${ }^{3,4+}$ and Verneri Anttila, $5,6,7+$
}

\begin{abstract}
Recent technical advances in genetics made large-scale genome-wide association studies (GWAS) in migraine feasible and have identified over 40 common DNA sequence variants that affect risk for migraine types. Most of the variants, which are all single nucleotide polymorphisms (SNPs), show robust association with migraine as evidenced by the fact that the vast majority replicate in subsequent independent studies. However, despite thorough bioinformatic efforts aimed at linking the migraine risk SNPs with genes and their molecular pathways, there remains quite some discussion as to how successful this endeavour has been, and their current practical use for the diagnosis and treatment of migraine patients. Although existing genetic information seems to favour involvement of vascular mechanisms, but also neuronal and other mechanisms such as metal ion homeostasis and neuronal migration, the complexity of the underlying genetic pathophysiology presents challenges to advancing genetic knowledge to clinical use. A major issue is to what extent one can rely on bioinformatics to pinpoint the actual disease genes, and from this the linked pathways. In this Commentary, we will provide an overview of findings from GWAS in migraine, current hypotheses of the disease pathways that emerged from these findings, and some of the major drawbacks of the approaches used to identify the genes and pathways. We argue that more functional research is urgently needed to turn the hypotheses that emerge from GWAS in migraine to clinically useful information.
\end{abstract}

Keywords: Genetics, Genome-wide association study, Disease pathway, Single-nucleotide polymorphism

\section{Background}

It has long been recognised that migraine is a disease with a strong genetic component [1-3]. Migraine runs in families, and epidemiological studies in twins and families have indicated that risk for migraine is conferred by a combination of genetic and environmental factors, both contributing equally $[2,3]$. These studies also indicated that the genetic contribution seems stronger in migraine with aura than the more common migraine without aura subtype. Considerable progress has been made with elucidating the pathophysiological mechanisms in migraine. Evidence is accumulating that cortical spreading depolarisation (CSD) is the electrophysiological substrate of the

\footnotetext{
* Correspondence: a.m.j.m.van_den_Maagdenberg@lumc.nl

Written for special Issue Journal of Headache and Pain

${ }^{\dagger}$ Dale R. Nyholt and Verneri Anttila contributed equally to this work.

'Department of Human Genetics, Leiden University Medical Centre, Leiden,

The Netherlands

2Department of Neurology, Leiden University Medical Centre, 9600, 2300 RC

Leiden, The Netherlands

Full list of author information is available at the end of the article
}

migraine aura $[4,5]$. Activation of the trigeminovascular system that consists of meningeal perivascular nerves, the trigeminal ganglion and brainstem centres reaches thalamus and ultimately the cortex to give the sensation of head pain in migraineurs during attacks [6]. Several animal studies showed that CSD can activate the headache mechanisms $[7,8]$, but proof that this also occurs in humans is essentially lacking. Knowledge on the underlying molecular mechanisms, to large extent, comes from genetic studies of very rare monogenic forms of migraine - i.e., hemiplegic migraine and syndromes in which migraine is prominent (for review see [9]). In brief, genes in familial hemiplegic migraine (FHM) (CACNA1A, $A T P 1 A 2$ and $S C N 1 A$ ) encode subunits of ion transporters (neuronal voltage-gated $\mathrm{Ca}_{\mathrm{V}} 2.1 \mathrm{Ca}^{2+}, \mathrm{Na}_{\mathrm{V}} 1.1 \mathrm{Na}^{+}$channels, and glial $\mathrm{Na}^{+} \mathrm{K}^{+}$ATPases, respectively) and functional studies in cellular and animal models suggest neuronal hyperexcitability as a common theme. Genes with vascular and/or glial cell function emerged from investigating syndromes in which migraine is prevalent, 
such as NOTCH3 in cerebral autosomal dominant arteriopathy with subcortical infarcts and leukoencephalopathy (CADASIL) and CSNK1D in familial advanced sleep phase syndrome (FASPS). Since one such high impact mutation is causative for disease, the identification of these genetic factors directly benefits the clinical diagnosis of patients with these rare disorders and may lead to the development of better treatment.

Parallel research aimed to identify genetic factors for the common forms of migraine, foremost migraine with aura and migraine without aura, suggests that these migraine types are brought about by a combination of multiple genetic variants, each with low impact, and environmental factors [10]. The most effective approach thus far to identify genetic factors for these forms of migraine are genome-wide association studies (GWAS), which test for differences in allele frequencies of several million single nucleotide polymorphisms (SNPs) spread over the genome in large groups of cases and controls [11]. Allelic differences at SNPs with a $p$-value $<5 \times 10^{-8}$ are taken as proof that a migraine risk factor is located at that position. Due to their small effect size (allelic odds ratio of 1.03-1.28), no single SNP can have clinical use in migraine risk prediction; however, one can envisage that combined knowledge from many variants will highlight which genes and pathways are involved in migraine pathophysiology, as well as more direct applications through approaches like polygenic risk scoring, where additive effects of multiple migraine risk SNPs can be used to score patients and then analyse those scores against clinical variables. Spearheaded by the International Headache Genetics Consortium (IHGC; www.headachegenetics.org/), which brought together headache geneticists and clinicians from around the globe, various large-scale association studies were conducted. Here we will review the main findings of their studies: the DNA variants that were identified, what efforts were made to link these to genes and molecular pathways, and whether any hypotheses emerged that may guide the development of migraine treatments.

\section{Main text}

\section{Genome-wide association studies in migraine}

In the past decade IHGC researchers have conducted several GWAS for migraine (for review see $[10,12]$ ). With increasing samples sizes available for investigation, the number of associated gene variants also increased. Initial sample sizes consisted of a few thousand patients with migraine with aura (in the 2010 GWAS [13]) or migraine without aura (in the 2012 GWAS [14]) that had been recruited in specialised headache clinics and yielded one and six associated SNPs, respectively. A SNP refers to a specific location on the genome with two alleles, indicated by an rs-number (e.g., rs9349379, the
Reference SNP cluster ID number for that SNP that is searchable in the SNP database [dbSNP: www.ncbi.nlm.nih.gov/SNP/]). In the 2011 GWAS [15], 5122 women with migraine from the Women's Genome Health Study were investigated and three associated SNPs were identified, two of which surfaced also in the 2012 GWAS. In more recent efforts, meta-analyses were performed on genotypic data of the previous cohorts that was combined with data of other cohorts to yield much larger groups of migraine patients; i.e., 23,285 cases in the 2013 GWAS [16] and 59,674 cases in the 2016 GWAS) [17], which led to 13 and 44 associated SNPs, respectively. In GWAS, genotypic information of migraine cases is compared with data of ever-increasing numbers (in the latest study $316,078)$ of control subjects. Notably, it is customary to not screen for (and remove) cases $(\sim 15 \%$ in the case of migraine) from the control sets that typically are from large population-based cohorts. An important message from these GWAS is that migraine-associated SNPs are generally very robust findings due to their stringent statistical methodology and consequently most of them have been replicated in subsequent studies. Secondly, all associated SNPs have a small genetic effect with allelic odds ratio of 1.03-1.28 (for the disease-increasing risk allele) [13-17], which resonates earlier claims that no single genetic factor is sufficient to cause migraine, which is no different for any other disorder studied with GWAS [18].

\section{The difficult road from associated SNPs to genes and mechanisms}

Whereas there is little doubt that the identified variants (indicated by their rs ID number) are genuine findings, robustly linking those variants to genes and pathways is difficult due to the complexity of local genomic effects. Firstly, most attention in literature goes to reporting the index SNP (i.e., the SNP with the lowest $p$-value in a genomic region), but there can be multiple independent association signals at the same locus, called secondary SNPs, which may affect, for example, other regulatory features of the same (or neighbouring) gene. The 2016 GWAS, with its 44 migraine-associated SNPs (associations were with the subtype migraine without aura), implicated 38 distinct genomic loci, of which six contained an independent secondary signal (Table 1).

Secondly, traditionally the most straightforward approach in interpreting a GWAS signal was to link the index SNP to the nearest gene, under evidence that regulatory effects tend to largely act on short distances $[19,20]$. The strength of this inference depends on a number of factors, such as the size and gene density of the identified locus; while long-range trans-eQTL ('expression quantitative trait loci' which explain small fractions of the genetic variance of a gene expression phenotype) effects exist in the genome, the preponderance towards 
Table 1 Migraine-associated single nucleotide polymorphisms and the molecular pathways they are linked to

\begin{tabular}{|c|c|c|c|c|c|c|}
\hline $\begin{array}{l}\text { Genomic } \\
\text { region }^{\mathrm{a}}\end{array}$ & $\begin{array}{l}\text { Index } \\
\text { SNP }\end{array}$ & $\begin{array}{l}\text { Secondary } \\
\text { SNPC }^{c}\end{array}$ & $\begin{array}{l}\text { Gene nearest } \\
\text { index SNP }\end{array}$ & $\begin{array}{l}\text { Genes overlapping } \\
\text { credible SNPS }\end{array}$ & $\begin{array}{l}\text { Genes prioritised } \\
\text { with DEPICT }\end{array}$ & Pathways identified with g:GOSt tool \\
\hline \multirow[t]{2}{*}{1} & rs10218452 & & PRDM16 & PRDM16 & PRDM16 & Vascular function; Metal ion homeostasis \\
\hline & & rs12135062 & & & & \\
\hline 2 & rs1572668 & & LRR/Q3 & & & \\
\hline \multirow[t]{2}{*}{3} & rs2078371 & & TSPAN2 & & NGF & \\
\hline & & rs7544256 & & & & \\
\hline 4 & rs6693567 & & ADAMTSL4 & RPRD2 & ECM1 & Vascular function \\
\hline 5 & rs1925950 & & MEF2D & MEF2D & & Vascular function \\
\hline 6 & rs138556413 & & CARF & CARF & NBEAL1 & \\
\hline \multirow[t]{2}{*}{7} & rs10166942 & & TRPM8 & TRPM8 & & Ion channel activity \\
\hline & & rs566529 & & & & \\
\hline 8 & rs6791480 & & TGFBR2 & & TGFBR2 & Vascular function; Metal ion homeostasis \\
\hline 9 & rs13078967 & & GPR149 & & ARHGEF26 & Vascular function \\
\hline 10 & rs7684253 & & SPINK2 & & REST & $\begin{array}{l}\text { Vascular function; Metal ion homeostasis; } \\
\text { Ion channel activity }\end{array}$ \\
\hline 11 & rs9349379 & & PHACTR1 & PHACTR1 & & Vascular function \\
\hline 12 & rs140002913 & & NOTCH4 & & & \\
\hline 13 & rs10456100 & & KCNK5 & KCNK5 & & Ion channel activity \\
\hline \multirow[t]{2}{*}{14} & rs67338227 & & FHL5 & FHL5 & & Vascular function \\
\hline & & rs4839827 & & & & \\
\hline 15 & rs28455731 & & GJA1 & & GJA1 & Vascular function \\
\hline 16 & rs1268083 & & HEY2 & HEY2, NCOA7 & HEY2 & Vascular function \\
\hline 17 & rs186166891 & & SUGCT & SUGCT & & \\
\hline 18 & rs10155855 & & DOCK4 & & & \\
\hline 19 & rs6478241 & & ASTN2 & ASTN2 & & \\
\hline 20 & rs2506142 & & NRP1 & NRP1 & NRP1 & Vascular function; Metal ion homeostasis \\
\hline \multirow[t]{2}{*}{21} & rs10786156 & & PLCE1 & PLCE1 & PLCE1 & Vascular function \\
\hline & & rs75473620 & & & & \\
\hline 22 & rs12260159 & & HPSE2 & HPSE2 & HPSE2 & \\
\hline 23 & rs2223089 & & ARMS2 & PLEKHAI, HTRA1 & HTRA1 & Vascular function \\
\hline 24 & rs4910165 & & MRVI1 & MRVI1 & MRVI1 & \\
\hline 25 & rs11031122 & & MPPED2 & MPPED2 & & \\
\hline 26 & rs10895275 & & YAP1 & YAP1 & YAP1 & Vascular function \\
\hline 27 & rs561561 & & IGSF9B & IGSF9B & & \\
\hline 28 & rs1024905 & & FGF6 & & FGF6 & Vascular function \\
\hline \multirow[t]{2}{*}{29} & rs11172113 & & LRP1 & $\angle R P 1$ & LRP1 & Vascular function; Metal ion homeostasis \\
\hline & & rs11172055 & & & & \\
\hline 30 & rs11624776 & & ITPK1 & & & \\
\hline 31 & rs77505915 & & CFDP1 & CFDP1, TMEM170A & & \\
\hline 32 & rs4081947 & & ZCCHC14 & & $\mathrm{ZCCHC14}$ & Vascular function; Metal ion homeostasis \\
\hline 33 & rs75213074 & & WSCD1 & & & \\
\hline 34 & rs17857135 & & RNF213 & RNF213 & & Metal ion homeostasis \\
\hline 35 & rs111404218 & & $J A G 1$ & & $J A G 1$ & Vascular function; Metal ion homeostasis \\
\hline
\end{tabular}


Table 1 Migraine-associated single nucleotide polymorphisms and the molecular pathways they are linked to (Continued)

\begin{tabular}{|c|c|c|c|c|c|c|}
\hline $\begin{array}{l}\text { Genomic } \\
\text { region }^{\mathrm{a}}\end{array}$ & $\begin{array}{l}\text { Index } \\
\text { SNPb }\end{array}$ & $\begin{array}{l}\text { Secondary } \\
\text { SNPC }\end{array}$ & $\begin{array}{l}\text { Gene nearest } \\
\text { index SNP }\end{array}$ & $\begin{array}{l}\text { Genes overlapping } \\
\text { credible SNPs }\end{array}$ & $\begin{array}{l}\text { Genes prioritised } \\
\text { with DEPICT }\end{array}$ & Pathways identified with g:GOSt tool \\
\hline 36 & rs4814864 & & SLC24A3 & SLC24A3 & & Ion channel activity \\
\hline 37 & rs144017103 & & CCM2L & CCM2L & CCM2L & Vascular function \\
\hline 38 & rs12845494 & & MED14 & & & \\
\hline
\end{tabular}

${ }^{\mathrm{a}}$ Genomic region is an independent genomic region (> $250 \mathrm{~kb}$ apart) that harbours at least one migraine risk SNP; ${ }^{\mathrm{b}}$ Index SNP is the SNP with the lowest $p$-value at a genomic region. ' ${ }^{C}$ Secondary SNP is a genome-wide significant SNP that is not in linkage disequilibrium with the index SNP. Associations were identified for the migraine without aura subtype. DEPICT, data-driven expression-prioritized integration for complex traits; g:GOSt tool refers to web-based gene functional profiling software g:Profiler128 (http://biit.cs.ut.ee/gprofiler/) (depicted are only the more prominent pathways vascular function, metal ion homeostasis, ion channel activity pathways) (Compiled and adapted from [17, 33])

short distance cis-eQTLs suggest we can be fairly confident in linking a locus where only a single gene resides within the associated SNPs to hypothesise about function. One way to combat this is to combine the evidence from association-test statistics with linkage disequilibrium information (i.e., prior information on how haplotype patterns [alleles of close by SNPs] behave at each locus) in a Bayesian approach [21], to define what is called a credible set of SNPs (i.e., the set of SNPs that with a $99 \%$ chance contain the causal SNP at a locus). Using the genomic location of the credible SNPs the most likely gene(s) associated with migraine were identified (Table 1). Since causal variants are often located in intronic or intergenic regions in gene-dense areas, inferring which of the many genes within the credible set is involved based on SNP data alone can be tricky. In practice, this means that all the genes at such loci need to be taken forward to post-hoc analyses, which imposes power challenges to such analyses. Information on the gene's function and participation in known biological pathways can be used to prioritise causative genes using methods such as DEPICT [22], which prioritises genes if their predicted function is shared with that of genes at other associated loci more often than expected. Together, analysis of credible SNPs and DEPICT analysis identified 37 genes that are likely to be causal (Table 1).

Thirdly, even in cases where only a single gene is implicated, the complexity of gene regulation can provide additional challenges; this was clearly demonstrated by the fact that intronic SNP rs9349379 that had been linked in this way to PHACTR1 in multiple migraine GWAS (as well as coronary artery disease, cervical artery dissection, fibro-muscular dysplasia, and hypertension) and where the credible set comprises only rs9349379, detailed functional follow-up analyses revealed that this SNP influences the expression of EDN1 (coding for endothelin-1 (ET-1), 600,000 base pairs [bp] upstream) [23]. ET-1 is a potent vasoconstrictor that acts on smooth muscle cells and has previously been implicated in migraine [24]. Although hypothesis-free methods such as GWAS and sequencing studies are meant to provide the roadmap towards core pathophysiology of a disease, they rely on direct and well-designed 'wet-lab' functional follow-ups to nail down the key molecular mechanisms. As the type of assay, whether animal- or cell-based, needed for a functional follow-up very much depends on the actual variant and the gene it affects, it is not possible to give specific directions on how to go about for a particular variant (for recent reviews on technical possibilities see $[25,26])$.

\section{Emerging molecular pathways from GWAS hits?}

The most profound hypothesis that emerged from the 2016 IHGC GWAS publication [17] (with only a minute fraction of the genes/loci identified thus far) was the enrichment of genes involved in the vascular system among the identified genetic risk factors for migraine. Briefly, tissue expression enrichment analysis was performed, where the expression of genes (from GTEx data) within 50,000 bp of credible-set SNPs was assessed in 42 different human tissue types. These analyses identified that arterial and gastrointestinal tissues were significantly enriched for expression of migraine-associated genes. Indeed, no less than 15 of the implicated genes are related to vascular function of which four (MEF2D, YAP1, LRP1, JAG1) were significantly enriched in vascular tissues, as shown by in silico tissue expression enrichment analysis [17].

The 2016 gene expression enrichment results suggested that vascular dysfunction is important in migraine susceptibility and fuelled the long-running debate whether migraine is a disease of vascular dysfunction, or of neuronal dysfunction with vascular changes playing a secondary role. However, the 2016 finding by no means suggests that a neuronal origin of migraine is now excluded, already because at least five genes (PRDM16, MEF2D, FHL5, ASTN2, LRP1) (also) have a neuronal function. Another, rather unexpected, hypothesis that emerges is that metal ion homeostasis might contribute to migraine susceptibility, as 11 genes (PRDM16, TGFBR2, REST, FHL5, NRP1, MMPED2, LRP1, ZCCHC14, RNF213, JAG1, SLC24A3) with such function are among the 37 genes. Of note, ion channel activity (TRPM8, REST, KCNK5, SLC24A3), which emerged from genetic studies in monogenic FHM, and pain signalling (TRPM8) were much less prominent signals [27]. 
A more recent [28] tissue enrichment analysis of the 2016 IHGC GWAS summary statistics - utilising two gene expression datasets (GTEx and 'Franke lab') and chromatin data (highlighting active regulatory regions) from the Roadmap Epigenomics and ENCODE (EN-TEx) projects - reported enrichment of both vascular and neurological enrichment. More specifically, cardiovascular enrichments were found for migraine without aura with gene expression data, and for migraine without aura and 'all' migraine with EN-TEx data. Whereas, analysis using Roadmap data found the strongest enrichment for migraine (all subtypes) was neurological (neurospheres and fetal brain, neither of which were present in GTEx and EN-TEx). These results highlight the importance utilising multiple tissues, cell types and regulatory measures in such enrichment analyses aimed at interpreting GWAS risk loci.

It is useful to keep in mind that a GWAS SNP only 'tags' the disease locus, implying that the identified SNP is only correlated - because of linkage disequilibrium - with the disease-causing variant, which is not the end of the road' as far as understanding the functional consequences. Efforts at combining information across phenotypes either directly at the summary statistic phase [29] or by comparative analysis of correlated phenotypes [30] as well as increasing the size of the migraine GWAS itself (leading to more implicated loci) will yield improvements on the locus side of the analysis; concurrently, considerable efforts are being focused on improving the quality of the next layer of information, which links SNPs to function, through various -omics studies assaying the genome in general $[26,31]$, and the improvement of these resources and better methodology will increase the statistical power on the post-hoc side of the analysis. However, it is crucial to realise that rapid progress can also be made in migraine specifically by targeted follow-ups (such as for the rs9349379/EDN1/ET-1 study) [23], given that we now have a set of well-characterised loci waiting for such detailed characterisation. For example, several of the mechanisms implied by the two latest GWAS (such as regulation of vascular tone, ion homeostasis) may present directly testable hypotheses.

\section{What lies ahead?}

GWAS in migraine have been fruitful in the sense that they yielded several dozens of robustly identified loci in the genome that harbour genetic risk factors. Despite clear challenges how to link associated SNPs to actual genes and pathways, the likelihood that the correct genes are identified is increased by bioinformatics tools. Emerging hypotheses suggest that vascular function and metal ion homeostasis are among the pathways involved in migraine pathophysiology. Other pathways such as neuronal function and ion channel activity are less prominent among the genes identified thus far. Current initiatives of IHGC to conduct even larger GWAS (close to $100 \mathrm{~K}$ cases) appear to identify many more risk loci $(>100)$ [32] that may support current hypotheses and likely generate new ones. Over time, the genetic landscape of migraine will be more complete so one may predict migraine risk using approaches like polygenic risk scores, which is not yet sufficiently accurate [33-35]. One major challenge will be to elucidate the functional consequences of the associated SNPs and identify how they may affect migraine risk at the individual level. Efforts to functionally characterise GWAS signals, for other diseases than migraine, have been considering high-throughput cell-based (e.g., induced pluripotent stem cells [iPSCs]) and animal models (e.g., Drosophila) [26]. Considerable amount of research is needed before migraine GWAS findings will show diagnostic or prognostic value and lead to the development of (personalised) treatment options.

\section{Abbreviations \\ CADASIL: Cerebral autosomal dominant arteriopathy with subcortical infarcts and leukoencephalopathy; CSD: Cortical spreading depolarisation; \\ DEPICT: Data-driven expression-prioritized integration for complex traits; \\ FASPS: Familial advanced sleep phase syndrome; FHM: Familial hemiplegic \\ migraine; GWAS: Genome-wide association study; IHGC: International \\ Headache Genetics Consortium; SNP: Single nucleotide polymorphism}

\section{Acknowledgements}

None

Funding

No funding was obtained for this review.

Availability of data and materials

Not applicable.

Authors' contributions

All authors co-wrote and revised the manuscript. All authors read and approved the final manuscript.

Ethics approval and consent to participate

Not applicable.

Consent for publication

All authors gave consent to publication of the paper.

Competing interests

The authors declare that they have no competing interests.

\section{Publisher's Note}

Springer Nature remains neutral with regard to jurisdictional claims in published maps and institutional affiliations.

\section{Author details}

${ }^{1}$ Department of Human Genetics, Leiden University Medical Centre, Leiden, The Netherlands. ${ }^{2}$ Department of Neurology, Leiden University Medical Centre, 9600, 2300 RC Leiden, The Netherlands. ${ }^{3}$ School of Biomedical Sciences, Faculty of Health, Queensland University of Technology, Brisbane, QLD, Australia. ${ }^{4}$ Institute of Health and Biomedical Innovation, Queensland University of Technology, Brisbane, QLD, Australia. ${ }^{5}$ Analytical and

Translational Genetics Unit, Department of Medicine, Massachusetts General Hospital and Harvard Medical School, Boston, MA, USA. 'Stanley Center for Psychiatric Research, Broad Institute of MIT and Harvard, Cambridge, MA, USA. ${ }^{7}$ Program in Medical and Population Genetics, Broad Institute of MIT and Harvard, Cambridge, MA, USA. 
Received: 5 October 2018 Accepted: 27 December 2018 Published online: 11 January 2019

\section{References}

1. Sutherland HG, Griffiths LR (2017) Genetics of Migraine: Insights into the Molecular Basis of Migraine Disorders. Headache 57:537-569

2. Gervil M, Ulrich V, Kaprio J, Olesen J, Russell MB (1999) The relative role of genetic and environmental factors in migraine without aura. Neurology 53: 995-999

3. Mulder EJ et al (2003) Genetic and environmental influences on migraine: a twin study across six countries. Twin Res 6:422-431

4. Lauritzen M (1994) Pathophysiology of the migraine aura. The spreading depression theory. Brain 117:199-210

5. Hadjikhani N, Sanchez Del Rio M, Wu O, Schwartz D, Bakker D, Fischl B, Kwong KK, Cutrer FM, Rosen BR, Tootell RB, Sorensen AG, Moskowitz MA (2001) Mechanisms of migraine aura revealed by functional MRI in human visual cortex. Proc Natl Acad Sci USA 98:4687-4692

6. Goadsby PJ, Holland PR, Martins-Oliveira M, Hoffmann J, Schankin C, Akerman S (2017) Pathophysiology of Migraine: A Disorder of Sensory Processing. Physiol Rev 97:553-622

7. Noseda R, Burstein R (2013) Migraine pathophysiology: anatomy of the trigeminovascular pathway and associated neurological symptoms, cortical spreading depression, sensitization, and modulation of pain. Pain 154(Suppl 1):S44-S53

8. Karatas H, Erdener SE, Gursoy-Ozdemir Y, Lule S, Eren-Koçak E, Sen ZD, Dalkara T (2013) Spreading depression triggers headache by activating neuronal Panx1 channels. Science 339:1092-1095

9. Ferrari MD, Klever RR, Terwindt GM, Ayata C, van den Maagdenberg AM (2015) Migraine pathophysiology: lessons from mouse models and human genetics. Lancet Neurol 14:65-80

10. Anttila V, Wessman M, Kallela M, Palotie A (2018) Genetics of migraine. Handb Clin Neurol 148:493-503

11. Wang MH, Cordell HJ, Van Steen K (2018) Statistical methods for genomewide association studies. Semin Cancer Biol. https://doi.org/10.1016/j. semcancer.2018.04.008

12. Nyholt DR, van den Maagdenberg AM (2016) Genome-wide association studies in migraine: current state and route to follow. Curr Opin Neurol 29 : 302-308

13. Anttila $V$, Stefansson $H$, Kallela M, Todt U, Terwindt GM, Calafato MS, Nyholt DR, Dimas AS, Freilinger T, Müller-Myhsok B, Artto V, Inouye M, Alakurtti K, Kaunisto MA, Hämäläinen $E$, de Vries $B$, Stam AH, Weller $C M$, Heinze $A$, Heinze-Kuhn K, Goebel I, Borck G, Göbel H, Steinberg S, Wolf C, Björnsson A, Gudmundsson G, Kirchmann M, Hauge A, Werge T, Schoenen J, Eriksson JG, Hagen K, Stovner L, Wichmann HE, Meitinger T, Alexander M, Moebus S, Schreiber S, Aulchenko YS, Breteler MM, Uitterlinden AG, Hofman A, van Duijn CM, Tikka-Kleemola P, Vepsäläinen S, Lucae S, Tozzi F, Muglia P, Barrett J, Kaprio J, Färkkilä M, Peltonen L, Stefansson K, Zwart JA, Ferrari MD, Olesen J, Daly M, Wessman M, van den Maagdenberg AM, Dichgans M, Kubisch C, Dermitzakis ET, Frants RR, Palotie A (2010) International Headache Genetics Consortium. Genome-wide association study of migraine implicates a common susceptibility variant on 8q22.1. Nat Genet 42:869-873

14. Freilinger $T$, Anttila V, de Vries B, Malik R, Kallela M, Terwindt GM, PozoRosich P, Winsvold B, Nyholt DR, van Oosterhout WP, Artto V , Todt U, Hämäläinen E, Fernández-Morales J, Louter MA, Kaunisto MA, Schoenen J, Raitakari O, Lehtimäki T, Vila-Pueyo M, Göbel H, Wichmann E, Sintas C, Uitterlinden AG, Hofman A, Rivadeneira F, Heinze A, Tronvik E, van Duijn CM, Kaprio J, Cormand B, Wessman M, Frants RR, Meitinger T, MüllerMyhsok B, Zwart JA, Färkkilä M, Macaya A, Ferrari MD, Kubisch C, Palotie A, Dichgans M, van den Maagdenberg AM (2012) International Headache Genetics Consortium. Genome-wide association analysis identifies susceptibility loci for migraine without aura. Nat Genet 44:777-782

15. Chasman DI, Schürks M, Anttila V, de Vries B, Schminke U, Launer LJ, Terwindt GM, van den Maagdenberg AM, Fendrich K, Völzke H, Ernst F, Griffiths LR, Buring JE, Kallela M, Freilinger T, Kubisch C, Ridker PM, Palotie A, Ferrari MD, Hoffmann W, Zee RY, Kurth T (2011) Genome-wide association study reveals three susceptibility loci for common migraine in the general population. Nat Genet 43:695-698

16. Anttila V, Winsvold BS, Gormley P, Kurth T, Bettella F, McMahon G, Kallela M, Malik R, de Vries B, Terwindt G, Medland SE, Todt U, WL MA, Quaye L, Koiranen M, Ikram MA, Lehtimäki T, Stam AH, Ligthart L, Wedenoja J, Dunham I, Neale BM, Palta P, Hamalainen E, Schürks M, Rose LM, Buring JE,
Ridker PM, Steinberg S, Stefansson H, Jakobsson F, Lawlor DA, Evans DM, Ring SM, Färkkilä M, Artto V, Kaunisto MA, Freilinger T, Schoenen J, Frants RR, Pelzer N, Weller CM, Zielman R, Heath AC, PAF M, Montgomery GW, Martin NG, Borck G, Göbel H, Heinze A, Heinze-Kuhn K, FMK W, Hartikainen AL, Pouta A, van den Ende J, Uitterlinden AG, Hofman A, Amin N, Hottenga JJ, Vink JM, Heikkilä K, Alexander M, Muller-Myhsok B, Schreiber S, Meitinger T, Wichmann HE, Aromaa A, Eriksson JG, Traynor B, Trabzuni D, North American Brain Expression Consortium, UK Brain Expression Consortium, Rossin E, Lage K, SBR J, Gibbs JR, Birney E, Kaprio J, Penninx BW, Boomsma DI, van Duijn C, Raitakari O, Jarvelin MR, Zwart JA, Cherkas L, Strachan DP, Kubisch C, Ferrari MD, van den Maagdenberg AM, Dichgans M, Wessman M, Smith GD, Stefansson K, Daly MJ, Nyholt DR, Chasman D, Palotie A (2013) Genome-wide meta-analysis identifies new susceptibility loci for migraine. Nat Genet 45:912-917

17. Gormley P, Anttila V, Winsvold BS, Palta P, Esko T, Pers TH, Farh KH, CuencaLeon E, Muona M, Furlotte NA, Kurth T, Ingason A, McMahon G, Ligthart L, Terwindt GM, Kallela M, Freilinger TM, Ran C, Gordon SG, Stam AH, Steinberg S, Borck G, Koiranen M, Quaye L, Adams HH, Lehtimäki T, Sarin AP, Wedenoja J, Hinds DA, Buring JE, Schürks M, Ridker PM, Hrafnsdottir MG, Stefansson H, Ring SM, Hottenga JJ, Penninx BW, Färkkilä M, Artto V, Kaunisto M, Vepsäläinen S, Malik R, Heath AC, Madden PA, Martin NG, Montgomery GW, Kurki MI, Kals M, Mägi R, Pärn K, Hämäläinen E, Huang H, Byrnes AE, Franke L, Huang J, Stergiakouli E, Lee PH, Sandor C, Webber C, Cader Z, Muller-Myhsok B, Schreiber S, Meitinger T, Eriksson JG, Salomaa V, Heikkilä K, Loehrer E, Uitterlinden AG, Hofman A, van Duijn CM, Cherkas L, Pedersen LM, Stubhaug A, Nielsen CS, Männikkö M, Mihailov E, Milani L, Göbel H, Esserlind AL, Christensen AF, Hansen TF, Werge T, International Headache Genetics Consortium, Kaprio J, Aromaa AJ, Raitakari O, Ikram MA, Spector T, Järvelin MR, Metspalu A, Kubisch C, Strachan DP, Ferrari MD, Belin AC, Dichgans M, Wessman M, van den Maagdenberg AM, Zwart JA, Boomsma DI, Smith GD, Stefansson K, Eriksson N, Daly MJ, Neale BM, Olesen J, Chasman DI, Nyholt DR, Palotie A (2016) Meta-analysis of 375,000 individuals identifies 38 susceptibility loci for migraine. Nat Genet 48:856-866

18. Visscher PM, Wray NR, Zhang Q, Sklar P, McCarthy MI, Brown MA, Yang J (2017) 10 Years of GWAS Discovery: Biology, Function, and Translation. Am J Hum Genet 101:5-22

19. Kirsten H, Al-Hasani H, Holdt L, Gross A, Beutner F, Krohn K, Horn K, Ahnert P, Burkhardt R, Reiche K, Hackermüller J, Löffler M, Teupser D, Thiery J, Scholz M (2015) Dissecting the genetics of the human transcriptome identifies novel trait-related trans-eQTLs and corroborates the regulatory relevance of non-protein coding loci. Hum Mol Genet 24:4746-4763

20. Stranger BE, Nica AC, Forrest MS, Dimas A, Bird CP, Beazley C, Ingle CE, Dunning $M$, Flicek $P$, Koller D, Montgomery S, Tavaré S, Deloukas $P$, Dermitzakis ET (2007) Population genomics of human gene expression. Nat Genet 39:1217-1224

21. Wellcome Trust Case Control Consortium et al (2012) Bayesian refinement of association signals for 14 loci in 3 common diseases. Nat Genet 44:1294-1301

22. Pers TH, Karjalainen JM, Chan Y, Westra HJ, Wood AR, Yang J, Lui JC, Vedantam S, Gustafsson S, Esko T, Frayling T, Speliotes EK, Genetic Investigation of ANthropometric Traits (GIANT) Consortium, Boehnke M, Raychaudhuri S, Fehrmann RS, Hirschhorn JN, Franke L (2015) Biological interpretation of genome-wide association studies using predicted gene functions. Nat Commun 6:5890

23. Gupta RM, Hadaya J, Trehan A, Zekavat SM, Roselli C, Klarin D, Emdin CA, Hilvering CRE, Bianchi V, Mueller C, Khera AV, Ryan RJH, Engreitz JM, Issner R, Shoresh N, Epstein CB, de Laat W, Brown JD, Schnabel RB, Bernstein BE, Kathiresan SA (2017) Genetic Variant Associated with Five Vascular Diseases Is a Distal Regulator of Endothelin-1 Gene Expression. Cell 170:522-533

24. Iljazi A, Ayata C, Ashina M, Hougaard A (2018) The Role of Endothelin in the Pathophysiology of Migraine-a Systematic Review. Curr Pain Headache Rep 22:27

25. Cannon ME, Mohlke KL (2018) Deciphering the Emerging Complexities of Molecular Mechanisms at GWAS Loci. Am J Hum Genet 103(5):637-653

26. Dourlen P, Chapuis J, Lambert JC (2018) Using High-Throughput Animal or Cell-Based Models to Functionally Characterize GWAS Signals. Curr Genet Med Rep 6(3):107-115

27. Nyholt DR, Borsook D, Griffiths LR (2017) Migrainomics - identifying brain and genetic markers of migraine. Nat Rev Neurol 13:725-741

28. Finucane HK, Reshef YA, Anttila V, Slowikowski K, Gusev A, Byrnes A, Gazal S, Loh PR, Lareau C, Shoresh N, Genovese G, Saunders A, Macosko E, Pollack S, Brainstorm Consortium PJRB, Buenrostro JD, Bernstein BE, Raychaudhuri S, 
McCarroll S, Neale BM, Price AL (2018) Heritability enrichment of specifically expressed genes identifies disease-relevant tissues and cell types. Nat Genet 50:621-629

29. Turley P, Walters RK, Maghzian O, Okbay A, Lee JJ, Fontana MA, Nguyen-Viet TA, Wedow R, Zacher M, Furlotte NA, Magnusson P, Oskarsson S, Johannesson M, Visscher PM, Laibson D, Cesarini D, Neale BM, Benjamin DJ (2018) 23andMe Research Team; Social Science Genetic Association Consortium. Multi-trait analysis of genome-wide association summary statistics using MTAG. Nat Genet 50:229-237

30. Brainstorm Consortium (2018) Analysis of shared heritability in common disorders of the brain. Science 22:360

31. Wijmenga C, Zhernakova A (2018) The importance of cohort studies in the post-GWAS era. Nat Genet. 50:322-328

32. Hautakangas H, Gormley P, Auton A, Litterman N, Palotie A, Pirinen M, on behalf of the 23andMe Research team and International Headache Genetics Consortium (IHGC). Meta-analysis of migraine with over 93,000 cases and 730,000 controls identifies 124 risk loci; (PgmNr 2380/T). Presented at the 68th Annual Meeting of The American Society of Human Genetics, 2018, San Diego, CA, USA.

33. Gerring ZF, Nyholt DR (2016) Can we predict those at higher risk for migraine? Per Med. 13:205-207

34. de Los Campos G, Vazquez Al, Hsu S, Lello L (2018) Complex-Trait Prediction in the Era of Big Data. Trends Genet. 34:746-754

35. Chalmer MA, Esserlind AL, Olesen J, Hansen TF (2018) Polygenic risk score: use in migraine research. J Headache Pain. 19:29

Ready to submit your research? Choose BMC and benefit from:

- fast, convenient online submission

- thorough peer review by experienced researchers in your field

- rapid publication on acceptance

- support for research data, including large and complex data types

- gold Open Access which fosters wider collaboration and increased citations

- maximum visibility for your research: over $100 \mathrm{M}$ website views per year

At $\mathrm{BMC}$, research is always in progress.

Learn more biomedcentral.com/submissions 